F.T. Lundy ${ }^{1 *}$, I. About ${ }^{2}$, T.M. Curtis ${ }^{1}$, M.K. McGahon', G.J. Linden', C.R. Irwin', and I.A. El Karim ${ }^{1}$

\title{
PAR-2 Regulates Dental Pulp Inflammation Associated with Caries
}

\begin{abstract}
Protease-activated receptors (PARs) are G-proteincoupled receptors that are activated enzymatically by proteolysis of an N-terminal domain. The cleavage and activation of PARs by serine proteases represent a novel mechanism by which such enzymes could influence the host inflammatory response. The aim of this study was to determine whether PAR-2 expression and activation were increased in dental caries. Using immunohistochemistry, we showed PAR-2 to be localized to pulp cells subjacent to caries lesions, but minimally expressed by healthy pulp tissue. Trypsin and the PAR-2 agonist (PAR2-AP) activated PAR-2 in an in vitro functional assay. Endogenous molecules present in pulp cell lysates from carious teeth specifically activated PAR-2, but those from healthy teeth failed to do so. The activation of PAR-2 in vitro was shown to increase the expression of the pro-inflammatory mediator cyclo-oxygenase- 2 (COX-2), providing a mechanism whereby PAR-2 could modulate pulpal inflammation.
\end{abstract}

KEY WORDS: dental pulp, human, inflammation, PAR.

\section{INTRODUCTION}

Drotease-activated receptors (PARs) belong to the G-protein-coupled transmembrane receptor family. To date, 4 PARs have been identified: PAR-1, PAR-2, PAR-3, and PAR-4. All 4 families possess similar activation mechanisms. Rather than being activated by ligand occupancy, PAR activation involves recognition of an $\mathrm{N}$-terminal extracellular domain by proteases. Proteolytic cleavage of this domain exposes a new N-terminus, which interacts with domains in the second extracellular loop of the receptor to induce intracellular calcium mobilization (Hollenberg and Compton, 2002). PARs-1,-3, and -4 are activated by thrombin (Macfarlane et al., 2001), whereas trypsin, mast cell tryptase, elastase, cathepsin G, neutrophil protease-3, and gingipains (Uehara et al., 2003; Dale and Fredericks, 2005) are among the activators of PAR-2. The cleavage and activation of PAR-2 provide a mechanism whereby proteases can directly influence the inflammatory response. Although trypsin is defined as the prototypical PAR-2 activator, its significance in tissuespecific PAR-2 activation is controversial, since its abundance is limited outside the gastrointestinal tract. Thus, the physiological importance of PAR-2 activation relies on determining tissue-specific endogenous activators, many of which remain elusive.

In the absence of receptor cleavage, PARs can also be activated by peptide agonists that mimic the $\mathrm{N}$-terminus produced by proteolytic cleavage. The peptide PAR2-AP (corresponding to the N-terminal sequence SLIGKV-NH ${ }_{2}$ ) specifically activates PAR-2. Both trypsin and PAR-2 agonists have been shown to stimulate nuclear factor- $\mathrm{\kappa B}(\mathrm{NF \kappa B})$, supporting a role for PAR activation in pro-inflammatory signaling pathways (Macfarlane et al., 2000). Furthermore, neuropeptide release from dental pulp cells has been shown to be PAR-dependent (Tancharoen et al., 2005). The PAR family is expressed by a wide variety of cell types. However, the relative cellular specificity of PAR-2 (in comparison with other PARs) has highlighted PAR-2 antagonism as a potential target for therapeutic intervention in inflammation (Ferrell et al., 2008).

We hypothesized that PAR-2 expression and activation were coupled with the host inflammatory response to dental caries. To define a role for PAR-2 in caries, we sought to localize the expression and levels of PAR-2 in dental pulp from carious teeth (compared with healthy teeth) and to confirm receptor functionality in vitro. To investigate the mechanism whereby PAR-2 activation could contribute to pulpal inflammation in vivo, we sought to establish the presence of endogenous activators of PAR-2 and to determine the effects of PAR-2 activation in vitro on the expression of the pro-inflammatory mediator cyclo-oxygenase 2 (COX-2). 


\section{MATERIALS \& METHODS}

Ethical approval was obtained from the Office for Research Ethics Committees (NI) and complied with French legislation (informed consent and Institutional Review Board protocol approval).

\section{Immunohistochemistry}

Six immature third molars (healthy) and 6 first molars (carious) were obtained during routine treatment. Rehydrated paraffinembedded sections $(7 \mu \mathrm{m})$ were incubated with rabbit antihuman PAR-2 antibody (AbCam, Cambridge, UK) at a 1/100 dilution overnight at $4^{\circ} \mathrm{C}$. Staining was revealed by the labeled streptavidin-biotin method (LSAB) (DakoCytomation, Ft. Collins, CO, USA). Additional sections were stained with hematoxylin-eosin (to determine pulp histology) and with antivimentin (1/50; Dako). Negative controls were incubated with non-immune serum. Gingival epithelium, known to express PAR-2 (Lourbakos et al., 2001), was used as a positive control.

\section{Dental Pulp Cell Culture}

Dental pulp cells were derived from healthy molar teeth $(n=3)$ as previously described (El Karim et al., 2009). Dental pulp cells were cultured in DMEM supplemented with 10\% FCS, 100 $\mathrm{U} / \mathrm{mL}$ penicillin, and $100 \mu \mathrm{g} / \mathrm{mL}$ streptomycin. On reaching confluence, pulp cells were propagated at a 1:3 split ratio. Cells between passages 3 and 6 were used in the study.

\section{Detection of PAR-2 and Cox-2}

\section{PAR-2}

Cells were grown to confluence in T75 flasks and washed in HBSS. Cell lysates $(n=3)$ were prepared from cultured pulp cells derived from 3 different healthy teeth with the Cell Lytic MT reagent (Sigma-Aldrich, Dorset, UK) according to the manufacturer's instructions. Cell lysates were also prepared from pulp tissue extracted from healthy $(n=3)$ and carious $(n=$ 3) teeth by the same method.

\section{COX-2}

Dental pulp cells were cultured in 6-well plates $\left(3 \times 10^{4}\right.$ cells per well). Cells were rendered quiescent for $48 \mathrm{hrs}$ in $0.5 \%$ serum prior to treatment with $100 \mu \mathrm{M}$ PAR2-AP for $4 \mathrm{hrs}$. Control cells received no treatment. Cells were washed in Hanks' and underwent lysis for $30 \mathrm{~min}$ on ice in $10 \mathrm{mM}$ Tris- $\mathrm{HCl}(\mathrm{pH} 7.4)$, containing 1\% SDS and protease inhibitors (Roche, Welwyn Garden City, Hertfordshire, UK).

\section{SDS-PAGE and Western Blotting}

Cell lysates were adjusted for protein concentration (measured by the bicinchoninic acid assay), subjected to electrophoresis, and blotted onto nitrocellulose as previously described (El Karim et al., 2008). For PAR-2 detection, blots were incubated with rabbit anti-human PAR-2 (Santa Cruz Biotechnology, Santa Cruz, CA, USA) overnight at room temperature $(1 / 5000)$, followed by anti-rabbit horseradish peroxidase $(1 / 10,000$; Cell Signaling
Technology, Beverly, MA, USA). For COX-2 detection, blots were incubated with goat anti-human COX-2 antibody (1/100; Santa Cruz) and anti-goat horseradish peroxidase (1/1000; Immunopure, Pierce, Rockford, IL, USA), followed by chemiluminescent detection. Band intensity was measured with ImageJ software (http://rsb.info.nih.gov/ij/). Bands were scanned in triplicate and an average obtained. Expression of the housekeeping protein GAPDH was measured as normalization controls.

\section{Functional Assays}

Dental pulp cells were grown on coverslips and allowed to attach for $48 \mathrm{hrs}$ prior to experimental treatment. Intracellular $\mathrm{Ca}^{2+}$ concentration $\left(\left[\mathrm{Ca}^{2+}\right]_{\mathrm{i}}\right)$ measurements were performed by a $\mathrm{Ca}^{2+}$ fura-2 microfluorimetry assay (Scholfield and Curtis, 2000). Briefly, dental pulp cells were incubated with Fura-2AM $(5 \mu \mathrm{M})$ for $1 \mathrm{hr}$ at $37^{\circ} \mathrm{C}$ and then superfused with Hanks' solution, $\mathrm{pH} 7.4$, at $37^{\circ} \mathrm{C}$ in a perfusion bath mounted on the stage of an inverted microscope (Nikon Eclipse TE2000, Tokyo, Japan). Cells were stimulated with $100 \mu \mathrm{M}$ PAR-2 agonist (PAR2-AP), $10 \mathrm{nM}$ trypsin, or endogenous enzymes from healthy or carious pulp cell lysates (see below). Stimulation with endogenous enzymes from carious pulp tissue was also undertaken in the presence of the PAR-2 antagonist ENMD-1068 (500 $\mu \mathrm{M}$; Enzo Life Sciences, Exeter, UK). Cells were illuminated by 340-/380nm light from a dual monochromator (5-nm bandwidth) and light chopper (Cairn Research, Kent, UK). Emitted fluorescence was measured from the side port of the microscope via an adjustable rectangular window, a filter $(510 \mathrm{~nm})$, and a photoncounting photomultiplier tube in the light path. Fluorescence equipment was controlled by Acquisition Engine (Cairn) software (V1.1.5), which was also used for analysis of the fluorescence data. Background fluorescence was quantified by incubation of the cells with $5 \mathrm{mM} \mathrm{Mn}{ }^{2+}$ in $\mathrm{Ca}^{2+}$-free solution. Changes in the ratio of the background-corrected fluorescence emitted at each excitation wavelength $(R=F 340 / F 380)$ were used as a measure of changes in the cytoplasmic $\mathrm{Ca}^{2+}$ concentration (Grynkiewicz et al., 1985).

\section{Detection of Endogenous Enzymes from Dental Pulp}

Proteolytic activity in cell lysates from healthy $(n=3)$ and carious $(n=3)$ pulp tissue was measured with resorufin-labeled casein (Universal protease substrate; Roche, UK) in both the presence and the absence of the serine protease inhibitor Pefabloc SC (10 nM) (Roche, UK) for evaluation of the contributions of serine proteases to overall proteolytic activity.

\section{Data Analysis}

Data are presented as means $\pm \mathrm{SE}$. For statistical evaluation, we used the Student's $t$ test to test the difference in $\left[\mathrm{Ca}^{2+}\right]_{\mathrm{i}}$ between baseline and peak and the levels of COX-2 and PAR-2 expression. The level of significance was set as $P \leq 0.05$.

\section{RESULTS}

In carious teeth, a region containing infiltrated inflammatory cells was apparent in the dental pulp subjacent to the caries 
Table. Proteolytic Activity of Cell Lysates from Healthy and Carious Pulp Tissue in the Presence and Absence of the Serine Protease Inhibitor Pefabloc

\begin{tabular}{lc}
\hline Sample Assayed for Proteolytic Activity & OD $570 \mathrm{~nm} / \mathrm{mg}$ Protein \\
\hline Cell lysate from healthy pulp tissue & 9.33 \\
Cell lysate from healthy pulp tissue & 4.24 \\
(+ serine protease inhibitor) & \\
Cell lysate from carious pulp tissue & 9.70 \\
Cell lysate from carious pulp tissue & 5.48 \\
(+ serine protease inhibitor) & \\
\hline
\end{tabular}

lesion in sections stained with H\&E (Appendix Fig. 1A). Dental pulp expression of PAR-2 in carious teeth was localized to this area subjacent to the caries lesion (Appendix Fig. 1B). There was no apparent PAR-2 staining in surrounding regions of the dental pulp (Appendix Fig. 1B). At higher magnification, the PAR-2 staining subjacent to the caries lesions appeared to be localized to dental pulp fibroblast-like cells (Appendix Fig. 1C). Staining confirmed the presence of vimentin-expressing cells (in the region of the caries lesion), the majority of which in the dental pulp are fibroblasts (Appendix Fig. 1D). In healthy teeth, PAR-2 staining was weak (Appendix Fig. 1E). The negative control showed no immunoreactivity in the presence of nonimmune serum in place of primary antibody (Appendix Fig. 1F).

Proteolytic activity measurements of cell lysates of dental pulp tissue from both healthy and carious teeth revealed measurable in vivo levels of serine protease-like enzymes (Table). Expression of PAR-2 was further elucidated by Western blotting cell lysates from dental pulp cells grown in vitro. Immunoreactive protein bands confirmed the expression of PAR-2 by cultured pulp cells (Fig. 1A). Carious pulp tissue expressed PAR-2, but in healthy pulp, PAR-2 was barely detectable (Fig. 1B). Increased PAR-2 (normalized to GAPDH) was significantly higher in carious compared with healthy pulps (Fig. 1C).

We examined the functionality of PAR-2 in dental pulp cells by monitoring $\left[\mathrm{Ca}^{2+}\right]_{i}$. Cells were treated with the PAR-2 agonist, PAR2-AP $(100 \mu \mathrm{M})$ (Fig. 2A), the prototypical PAR-2activating enzyme trypsin (Fig. 2B,) cell lysates containing enzymes from carious dental pulp tissue (Fig. 2C), and cell lysates containing enzymes from healthy dental pulp (Fig. 2D). Treatments (Appendix Fig. 2A-2D) produced a statistically significant increase $[\mathrm{P} \leq 0.01$, (B); or $\mathrm{P} \leq 0.05(\mathrm{~A}, \mathrm{C})]$ in mean fluorescence ratio compared with baseline, except for enzymes prepared from healthy pulp tissue, which failed to evoke increased $\left[\mathrm{Ca}^{2+}\right]_{i}$ [not significant (NS), (D)]. Continuous exposure of pulp cells to enzymes from carious teeth induced a sustainable increase in $\left[\mathrm{Ca}^{2+}\right]_{\mathrm{i}}$ that was reduced to baseline in the presence of the PAR-2 antagonist (ENMD-1068), indicating specific PAR-2-mediated calcium mobilization (Fig. 2E).

Western blotting to determine the effect of PAR-2 activation on COX-2 levels in vitro showed up-regulation of COX-2 following treatment with PAR2-AP compared with untreated cells. Increased COX-2 expression (normalized for GAPDH) after PAR2-AP treatment was shown to be statistically significant $(\mathrm{P}<0.001)$ (Figs. 3A,3B).
$\mathbf{A}$
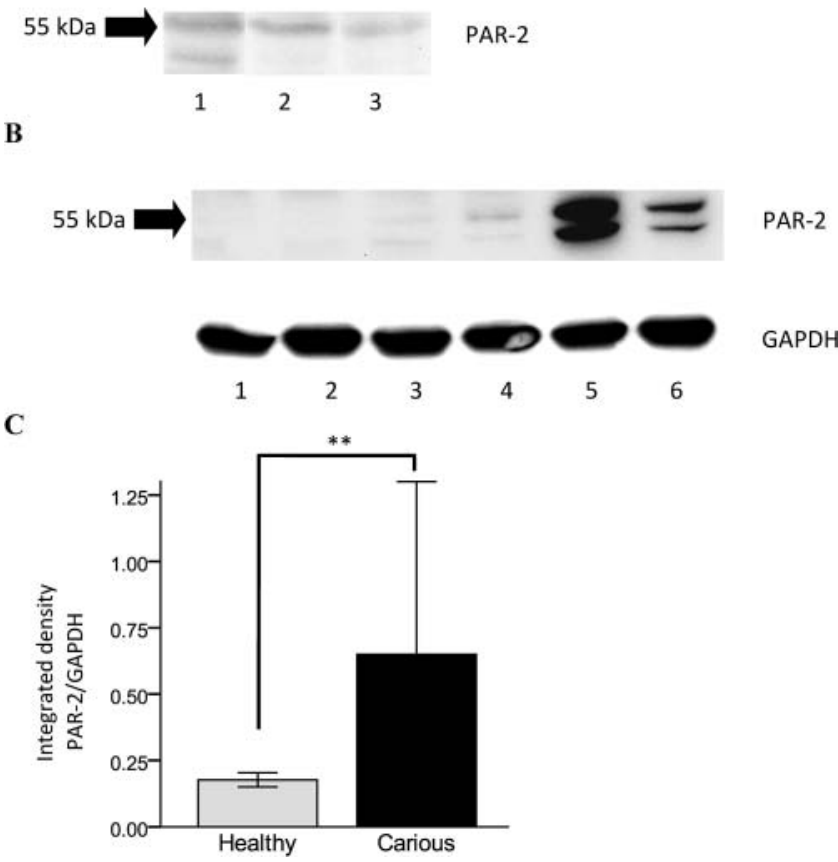

Figure 1. The expression of PAR-2 was studied by Western blotting. (A) Western blot showing immunoreactivity of PAR-2 in cell lysates $(n=3)$ prepared from dental pulp cells in vitro. Lanes 1, 2, and 3 represent 3 different dental pulp cell cultures. (B) Western blot showing immunoreactivity of PAR-2 in lysates prepared from healthy $(n=3)$ and carious $(n=3)$ teeth. Lanes 1,2 , and 3 represent healthy teeth; lane 4 represents a mildly carious tooth, and lanes 5 and 6 represent moderately carious teeth. (C) Expression of PAR-2/GAPDH is increased significantly in carious teeth compared with healthy teeth (**P $<0.001)$.

\section{DISCUSSION}

In the present study, we demonstrated a role for PAR-2 in the inflammatory response associated with dental caries. PAR-2 staining was shown to be localized to dental pulp cells in the area of the pulp subjacent to the caries lesion. Our results concur with those of previous studies suggesting that quiescent tissue fibroblasts constitutively express minimal PAR-2 in vivo (D'Andrea et al., 2001). Cultured lung and skin fibroblasts have previously been shown to express PAR-2 in vitro, but PAR-2 is rarely expressed by these cells in situ (Gruber et al., 2004). In the current study, spindle-shaped, vimentin-expressing dental pulp cells expressed PAR-2 in carious teeth in vivo, supporting the view that these are likely to be dental pulp fibroblast-like cells (Tancharoen et al., 2005; Morgan et al., 2009). The restriction of PAR-2 expression to the area of caries ingress suggests tight control over its expression in vivo. Receptor cleavage is an irreversible process, after which it is targeted to the lysosome (Hollenberg and Compton, 2003). Thus, further activation requires de novo synthesis or mobilization of receptors from intracellular storage (Fiorucci and Distrutti, 2002). The capacity of the dental pulp to respond to proteases therefore appears to be selectively increased by PAR-2 expression in the region of the caries lesion only. 
A

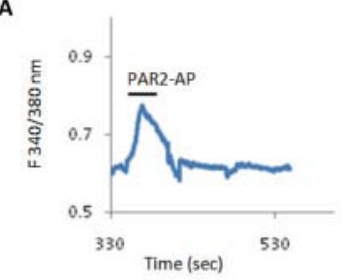

C

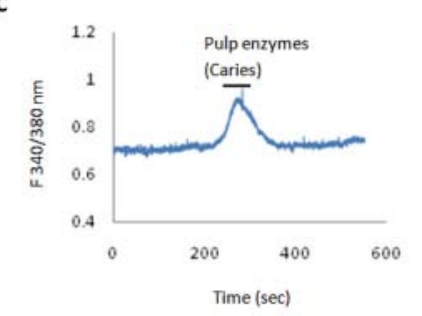

E

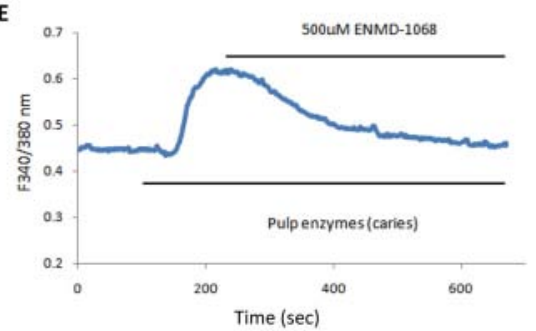

Figure 2. Functionality of PAR-2 in dental pulp cells. Fluorescence ratio measurements $\left(\mathrm{F}_{340} / \mathrm{F}_{380}\right)$ from individual cells exposed to (A) $100 \mu \mathrm{M}$ PAR2-AP. (B) $10 \mathrm{nM}$ Trypsin. (C) Pulpal enzymes in cell lysates prepared from carious dental pulp. (D) Pulpal enzymes in cell lysates prepared from healthy dental pulp. Pulp cells responded to agonists (A-C) by increases in $\left[\mathrm{Ca}^{2+}\right]_{\mathrm{i}}$, which returned to baseline following removal of the stimulus (horizontal bar). (E) PAR-2 activation by endogenous enzymes from carious pulp tissue was reduced to baseline by the PAR-2 antagonist, ENMD-1068 (upper horizontal bar), even in the presence of continued stimulation with pulp enzymes (lower horizontal bar), suggesting that $\left[\mathrm{Ca}^{2+}\right]_{i}$ mobilization is PAR-2-mediated.

During inflammation, IL-1 $\beta$ and TNF- $\alpha$ induce PAR-2, whereas TGF- $\beta$ down-regulates PAR-2 (Xiang et al., 2006). Our results support the activation of up-regulated PAR-2 by endogenous proteases abundant during the inflammatory response. The search for endogenous tissue-specific activators of PAR-2 is an important one, given that the prototypical PAR2-activating enzyme, trypsin, is unlikely to have physiological significance beyond the gastrointestinal tract. In this study, we showed measurable levels of serine-protease activity in both healthy and carious pulp tissue. However, only enzymes isolated from carious pulp tissue were capable of activating PAR-2, which were blocked by specific PAR-2 antagonism. These results reinforce the stringent control of PAR-2 activation in the dental pulp, not only through limitation of PAR-2 expression, but also by additional regulation of receptor activation. Several factors influence the ability of enzymes to activate PAR-2, including the availability of glycosaminoglycans and the glycosylation status of the receptor (Compton et al., 2001; Amadesi and Bunnett, 2004). Variable receptor glycosylation also affects the numbers and molecular weights of bands detected by
A
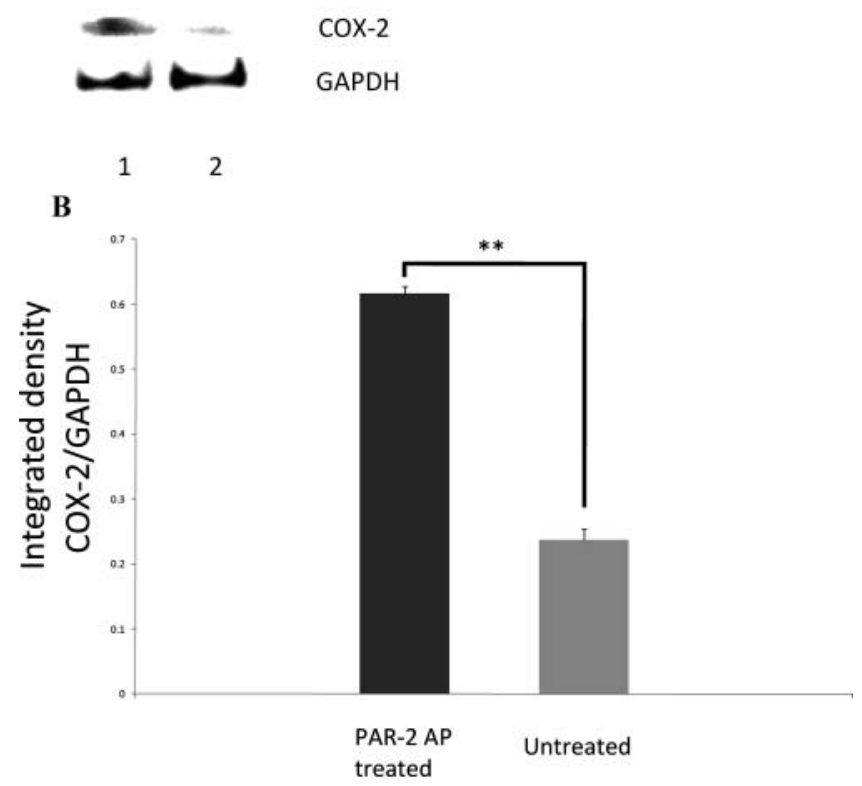

Figure 3. Activation of PAR-2 induces COX-2 expression in dental pulp fibroblasts in vitro. (A) Western blot showing up-regulation of COX-2 following treatment with the PAR-2 agonist PAR-2AP (Lane 1) compared with untreated cells (Lane 2). (B) Expression of COX-2/GAPDH is increased significantly after PAR-2AP treatment compared with untreated controls (**P $<0.001)$.

Western blotting (Compton et al., 2001; Gruber et al., 2004). Our results concur with the 55-kDa band previously detected for PAR-2 in conjunctival fibroblasts (Asano-Kato et al., 2005).

The finding that enzymes from healthy dental pulp do not activate PAR-2 suggests that PAR-2 activation may have an exclusively pro-inflammatory role in dental pulp pathology. PAR-2 activation has long been associated with pro-inflammatory effects. PAR-2-deficient mice have attenuated inflammatory responses (Hyun et al., 2008), and activation of PAR-2 increases COX-2 expression in a human-lung-derived A459 epithelial cell line (Wang et al., 2008). The finding in the current study that PAR2-AP induces COX-2 up-regulation in vitro provides further evidence supporting the pro-inflammatory effects of PAR-2. Release of neuropeptides from trigeminal nociceptors (Patwardhan et al., 2006) and dental pulp cells (Tancharoen et al., 2005) as a result of PAR-2 activation has been reported, which could lead to pain and neurogenic inflammation. Several neuropeptides have pro-inflammatory effects, and release of these neuropeptides could potentiate pulpal inflammation (Lundy and Linden, 2004). Proteinases (gingipains) produced by the periodontal pathogen Porphyromonas gingivalis have been shown to activate PAR-2 on dental pulp cells (Tancharoen et al., 2005). However, inflammation in the dental pulp arises principally as a result of dental caries rather than periodontal pathogens. Our finding that enzymes isolated from carious pulp tissue activate PAR-2 provides the first evidence of endogenous activators of PAR-2 in dental caries. The demonstration of endogenous activators of PAR-2 in caries lesions supports an in vivo role for PAR-2 activation in caries which has not been reliably substantiated in other 
potential sites of PAR-2-mediated inflammation. Proteases released from host cells such as neutrophils (Uehara et al., 2002) or fibroblasts are potential sources of PAR-2-activating enzymes. Alternatively, PAR-2-activating enzymes could have a bacterial source. Further investigations are required to identify the precise source(s) of PAR-2-activating enzymes.

In conclusion, PAR-2 has been shown to regulate dental pulpal inflammation associated with caries. Importantly, proteases prepared from carious pulp tissue activated PAR-2 in vitro, whereas enzymes from healthy pulp tissue failed to do so. These findings lend support to the complexities of PAR-2 activation reported previously (Shpacovitch et al., 2007).

\section{ACKNOWLEDGMENTS}

The authors acknowledge the skillful technical assistance of Ms. Catherine Fulton and Ms. Leanne McIlreavy, and helpful discussions with Dr. Susan Hawthorne, Queen's University Belfast, and Dr. Perry Maxwell, Belfast Health and Social Care Trust. This study was supported by institutional funding from the French Ministère de l'education nationale, de l'enseignement supérieur et de la recherche.

\section{REFERENCES}

Amadesi S, Bunnett N (2004). Protease-activated receptors: protease signalling in the gastrointestinal tract. Curr Opin Pharmacol 4:551556.

Asano-Kato N, Fukagawa K, Okada N, Dogru M, Tsubota K, Fujishima H (2005). Tryptase increases proliferative activity of human conjunctival fibroblasts through protease-activated receptor-2. Invest Ophthal Vis Sci 46:4622-4626.

Compton SJ, Renaux B, Wijesuriya SJ, Hollenberg MD (2001). Glycosylation and the activation of proteinase-activated receptor 2 (PAR-2) by human mast cell tryptase. Br J Pharmacol 134:705-718.

D'Andrea MR, Derian CK, Santulli RJ, Andrade-Gordon P (2001). Differential expression of protease-activated receptors-1 and -2 in stromal fibroblasts of normal, benign, and malignant tissues. Am J Pathol 158:2031-2041.

Dale BA, Fredericks LP (2005). Antimicrobial peptides in the oral environment: expression and function in health and disease. Curr Issues Mol Biol 7:119-113.

El Karim IA, Lamey P-J, Linden GJ, Lundy FT (2008). Neuropeptide Y Y1 receptor in human dental pulp samples of noncarious and carious teeth. Int Endod J 41:850-855.

El Karim IA, Linden GJ, Irwin CR, Lundy FT (2009). Neuropeptides regulate expression of angiogenic growth factors in human dental pulp fibroblasts. $J$ Endod 35:829-833.

Ferrell RW, Lockhart CJ, Plevin R (2008). Protease-activated receptor-2 (PAR2): a potential new target in arthritis. Drugs of the Future 33:241-248.

Fiorucci S, Distrutti E (2002). Role of PAR2 in pain and inflammation. Trends Pharmacol Sci 23:153-155.
Gruber BL, Marchese MJ, Santiago-Schwarz F, Martin CA, Zhang J, Kew RR (2004). Protease-activated receptor-2 (PAR-2) expression in human fibroblasts is regulated by growth factors and extracellular matrix. J Invest Dermatol 123:832-839.

Grynkiewicz G, Poenie M, Tsien RY (1985). A new generation of $\mathrm{Ca}^{2+}$ indicators with greatly improved fluorescence properties. $\mathrm{J} \mathrm{Biol} \mathrm{Chem}$ 260:3440-3450.

Hollenberg MD, Compton SJ (2002). International Union of Pharmacology. XXVIII. Proteinase-activated receptors. Pharmacol Rev 54:203-217.

Hollenberg MD, Compton SJ (2003). Proteinase-activated receptor domains and signalling. Drug Dev Res 59:344-349.

Hyun E, Andrade-Gordon P, Steinhoff M, Vergnolle N (2008). Proteaseactivated receptor-2 activation: a major factor in intestinal inflammation. Gut 57:1222-1229.

Lourbakos A, Potempa J, Travis J, D'Andrea MR, Andrade-Gordon P, Santulli $\mathrm{R}$, et al. (2001). Arginine-specific protease from Porphyromonas gingivalis activates protease-activated receptors on human oral epithelial cells and induces interleukin-6 secretion. Infect Immun 69:5121-5130.

Lundy FT, Linden GJ (2004). Neuropeptides and neurogenic mechanisms in oral and periodontal inflammation. Crit Rev Oral Biol Med 15:82-98.

Macfarlane SR, Kanke T, Seatter M, Davenport E, Paul A, Plevin R (2000). Trypsin stimulates the NF kappa B signalling pathway in NCTC 2544 transfected with human protease-activated receptor-2. Br J Pharmacol 129:21P.

Macfarlane SR, Seatter MJ, Kanke T, Hunter GD, Plevin R (2001). Proteinase-activated receptors. Pharmacol Rev 53:245-282.

Morgan CR, Rodd HD, Clayton N, Boissonade FM (2009). Changes in proteinase-activated receptor 2 expression in the human tooth pulp in relation to caries and pain. J Orofac Pain 23:265-274.

Patwardhan AM, Diogenes A, Berg KA, Fehrenbacher JC, Clarke WP, Akopian AN, et al. (2006). PAR-2 agonists activate trigeminal nociceptors and induce functional competence in the delta opioid receptor. Pain 125:114-124.

Scholfield CN, Curtis TM (2000). Heterogeneity in cytosolic calcium regulation among different microvascular smooth muscle cells of the rat retina. Microvasc Res 59:233-242.

Shpacovitch V, Feld M, Bunnett NW, Steinhoff M (2007). Proteaseactivated receptors: novel PARtners in innate immunity. Trends Immunol 28:541-550.

Tancharoen S, Sarker KP, Imamura T, Biswas KK, Matsushita K, Tatsuyama S, et al. (2005). Neuropeptide release from dental pulp cells by RgpB via proteinase-activated receptor-2 signaling. J Immunol 174:5796-5804

Uehara A, Sugawara S, Muramoto K, Takada H (2002). Activation of human oral epithelial cells by neutrophil proteinase 3 through proteaseactivated receptor-2. J Immunol 169:4594-4603.

Uehara A, Muramoto K, Takada H, Sugawara S (2003). Neutrophil serine proteinases activate human nonepithelial cells to produce inflammatory cytokines through protease activated receptor 2. J Immunol 170:5690-5696.

Wang H, Wen S, Bunnett NW, Leduc R, Hollenberg MD, MacNaughton WK (2008). Proteinase-activated receptor-2 induces cyclooxygenase-2 expression through $\beta$-catenin and cyclic AMP-response element-binding protein. J Biol Chem 283:809-815.

Xiang Y, Masuko-Hongo K, Sekine T, Nakamura H, Yudoh K, Nishioka K, et al. (2006). Expression of proteinase-activated receptors (PAR)-2 in articular chondrocytes is modulated by IL- $1 \beta$, TNF- $\alpha$, and TGF- $\beta$. Osteoarthritis Cartilage 14:1163-1173. 